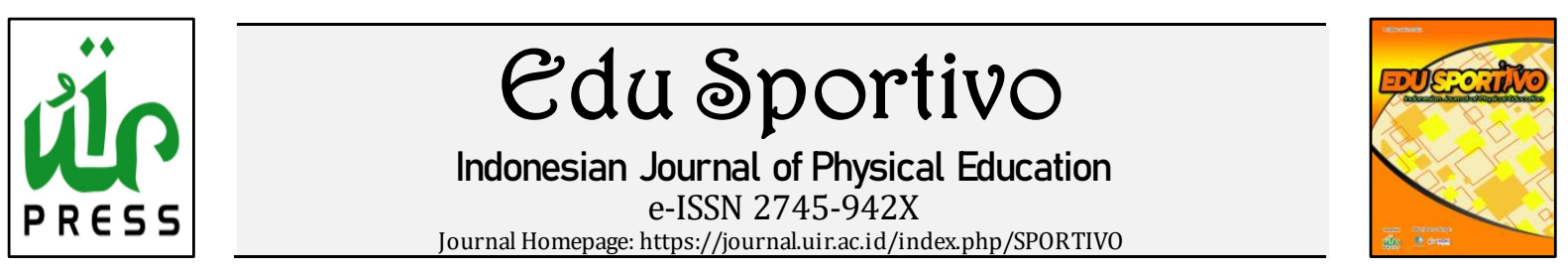

\title{
Penerapan media audio visual dalam meningkatkan hasil belajar dribble bolabasket
}

\section{The application of audio-visual media in improving dribble learning outcomes for basketball}

${ }^{1}$ Faizan Ramadhan, ${ }^{* 2}$ Mimi Yulianti, ${ }^{3}$ Raffly Henjilito

1 Sekolah Menengah Atas Negeri 3 Mandau, Bengkalis, Indonesia
*2,3 Pendidikan Jasmani Kesehatan dan Rekreasi, Universitas Islam Riau, Pekanbaru, Indonesia

Received: 07 June 2020; Accepted 09 August 2020; Published 10 August 2020

OPEN 2 ACCESS

\begin{tabular}{|c|c|}
\hline ABSTRAK & ABSTRACT \\
\hline $\begin{array}{l}\text { Tujuan penelitian ini adalah untuk meningkatkan hasil belajar } \\
\text { teknik menggiring bolabasket melalui metode media audio } \\
\text { visual pada permainan bolabasket kelas IX IPS } 5 \text { SMAN } 3 \\
\text { Mandau. Jenis penelitian ini adalah PTK, populasi dalam } \\
\text { penelitian berjumlah } 28 \text { siswa. Kemudian sampel yang } \\
\text { diambil adalah total sampling, yaitu seluruh populasi } \\
\text { sebanyak } 28 \text { siswa dijadikan sampel. Berdasarkan hasil } \\
\text { pengolahan data pada siklus I terdapat } 9 \text { siswa yang mencapai } \\
\text { nilai KKM (32\%), dan } 19 \text { siswa yang belum mencapai nilai } \\
\text { KKM (68\%). Ketuntasan klasikal tercapai saat mencapai } 80 \% \text {, } \\
\text { pada siklus II sebanyak } 25 \text { siswa telah mencapai nilai } \\
\text { ketuntasan } 89 \% \text {. Dan sebanyak } 3 \text { siswa yang belum mencapai } \\
\text { nilai } 11 \% \text {. Dengan demikian dapat disimpulkan bahwa } \\
\text { terdapat peningkatan yang sangat signifikan hasil belajar } \\
\text { menggiring bolabasket melalui media audio visual pada } \\
\text { olahraga bolabasket siswa kelas IX IPS } 5 \text { SMA N } 3 \text { Mandau } \\
\text { Kabupaten Bengkalis. }\end{array}$ & $\begin{array}{l}\text { The purpose of this study is to improvethe learningoutcomes } \\
\text { of basketball dribble techniques through the method of audio } \\
\text { visual media in basketball games class IX IPS } 5 \text { SMAN } 3 \\
\text { Mandau. This type of research is PTK, the population in the } \\
\text { study amounted to } 28 \text { students. then the sampletaken is total } \\
\text { sampling, which is the entire population of } 28 \text { students used } \\
\text { as samples. Based on the results of data processing in the first } \\
\text { cycle there were } 9 \text { students who achieved the KKM value } \\
(32 \%) \text {, and } 19 \text { students who had not yet achieved the KKM } \\
\text { value }(68 \%) \text {. Classical completeness is achieved when it } \\
\text { reaches } 80 \% \text {, in cycle II as many as } 25 \text { students have achieved } \\
\text { completeness value of } 89 \% \text {. And as many as } 3 \text { students who } \\
\text { have not yet reached the grade of } 11 \% \text {. Thus it can be } \\
\text { concluded that there is a very significant increase in } \\
\text { basketball dribble learning outcomes through audio-visual } \\
\text { media in the sport of basketball class IX IPS } 5 \text { SMA N } 3 \\
\text { Mandau Bengkalis Regency. }\end{array}$ \\
\hline Kata Kunci: Media; Audio Visual; Hasil Belajar; Bolabasket & $\begin{array}{l}\text { Keywords: Media; Audio Visual; Learning Outcomes; } \\
\text { Basketball }\end{array}$ \\
\hline $\begin{array}{l}\text { *Corresponding Author } \\
\text { Email: mimiyulianti@edu.uir.ac.id }\end{array}$ & $\begin{array}{l}\text { Copyright (c) } 2020 \\
\text { Edu Sportivo: Indonesian Journal of Physical Education }\end{array}$ \\
\hline
\end{tabular}

do

https://doi.org/10.25299/es:ijope.2020.vol1(1).5122

How To Cite: Ramadhan, F., Yulianti, M., \& Henjilito, R. (2020). Penerapan media audio visual dalam meningkatkan hasil belajar dribble bolabasket. Edu Sportivo: Indonesian Journal of Physical Education, 1(1), 50-59. https://doi.org/10.25299/es:ijop e.2020.vol1(1).5122.

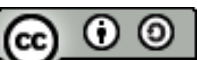

\section{PENDAHULUAN}

Olahraga mempunyai arti yang penting dalam usaha untuk meningkatkan kualitas sumber daya manusia. Olahraga tidak dapat dipisahkan dari kehidupan manusia, karena kehidupan manusia terdiri dari dua aspek, yaitu aspek jasmani dan rohani yang tidak dapat pisahkan. Jika kedua aspek tersebut berkembang dan tumbuh secara beselaras maka akan timbul kehidupan yang harmonis dalam pertumbuhannya. Olahraga memiliki tujuan untuk memelihara dan meningkatkan kebugaran serta dapat menanamkan nilai 
moral dan akhlak mulia, sportivitas, dan sebagainya. Di dalam pendidikan jasmani, terdapat cabang olahraga bolabasket yang termasuk dalam materi pokok pendidikan jasmani. Bolabaseket adalah permainan bola besar yang sangat menarik minat untuk ditonton dengan kraterisktik tertentu. Usaha memasukan bola ke dalam keranjang pihak lawan dan mencengah regu lawan untuk memasukan bola ke dalam keranjang sendiri adalah orientasi dan setiap tindakan dalam permainan bola basket. Permainan bolabasket memiliki nilai-nilai tertentu yang sifatnya universal. Banyak yang diperoleh dengan bermain bolabasket di antaranya adalah dapat membentuk sikap tubuh yang baik meliputi anatomis, fisiologis, kesehatan dan kemampuan jasmani dan manfaatnya bagi rohani dan kejiwaan, kepribadian, dan karakter akan tumbuh kearah yang sesuai dengan tuntunan masyarakat. Olahraga bolabasket berguna dalam pemiliharaan kesegaran jasmani dan juga berperan dalam pembentukan kerja siswa. Sebagaimana seperti cabang-cabang olahraga yang lain, bolabasket juga dapat digunakan untuk pembinaan sportifitas dan pengembangan sifat-sifat positif lainya.

Menurut Candra dan Wahyudi (2020) bolabasket adalah permainan tim, namun penguasaan teknik individual sangatlah penting sebelum bermain di dalam tim. Maka dalam permainan bolabasket terdapat beberapa teknik yang harus dikuasai oleh seorang pemain bolabasket agar dapat bermain dengan baik dan benar. Teknik dasar tersebut yaitu: (1) passing, (2) dribble, (3) shooting, (4) pivot atau cara berputar, (5) rebound. Dari kelima teknik dasar tersebut, penulis bermaksud mengadakan penelitian tentang teknik dribble yang baik dan dan benar. Dribble adalah bagian yang tidak dapat dipisahkan dari bolabasket dan penting bagi permainan induvidual dan tim. Sama seperti halnya passing, dribble juga salah satu cara membawa bola agar tetap bisa menguasai bola sambil bergerak dan bola harus dipantulkan di lantai. Dribble merupakan teknik dasar yang awal diajarkan buat pemain pemula dalam mempertahankan bola yang dikuasai. Gerakan teknik dribble melibatkan beberapa gerakan dari anggota badan yaitu: kontrol pada jarijari, kepala tegak, mempertahankan tubuh yang rendah, melindungi bola, dan melatih kedua tangan agar sama-sama dapat menggiring bola dengan baik.

Pada hakikatnya dribble merupkan teknik pokok yang dikuasai dalam bermain bolabasket, tetapi dribble mempuyai keungulan tersendiri dalam permainan bolabasket yaitu untuk memudahkan serangan fast break (serangan balik), lebih cepat menuju kegawang ring lawan, untuk menerobos perthanan lawan. Dribble bervariatif baik arah dan kecepatanya, selanjutnya memasukan bola ke dalam keranjang atau ring lawan bisa dikatakan hal yang menarik dalam permainan bola basket. Menurut Khoeron dalam (Perdima, 2017) mengatakan bahwa dribbling adalah sebuah pergerakan menggiring bola untuk menghindari lawan sampai mencetak poin. Teknik ini dilakukan dengan memantul-mantulkan bola ke lantai dengan ritme tertentu. Dribble juga dilakukan dengan cara memposisikan bola dengan badan. Dapat simpulkan dari kutipan di atas dribble adalah membawa bola dari segala arah sesuai dengan peraturan yang ada. Seorang diperbolehkan membawa bola lebih dari satu langkah asal bola dipantulkan ke lantai, baik dengan berjalan maupun berlari.

Dribble merupakan bagian yang tidak dapat dipisahkan dalam permaian olahraga bolabasket. Menurut Oliver (2009) dribble adalah salah satu teknik dasar bolabasket yang pertama diperkenalkan kepada para pemula karena keterampilan ini sangat penting bagi setiap pemain. Menurut Kosasih dalam Foekh dan Tausikal (2014) Mengatakan dribble adalah sautu teknik fudemental yang dilakukan dengan kekuatan dari siku, pergelangan tangan, telapak tangan, jari-jari dan sedikit bantuan dari bahu. Sedangkan Wissel (2000) menyatakan dribble adalah salah satu cara membawa bola agar tetap menguasai sambil bergerak, dan harus memantulkannya di lantai. Dari teori 
di atas dapat disimpulkan dribble sama hal dengan menjaga agar supaya tidak mudah direbut begitu saja maka pemain harus lebih aktif bergerak ke segala arah dalam mencari ruang utuk mendapatkan poin.

Liberman dalam Daharis dan Ramadhani (2018) Mengatakan kemampuan anda untuk menggiring bola dapat berdampak besar pada kemampuan tim anda untuk melakukan pelangaran. Daharis dan Ramadhani (2018) menambahkan dribble adalah cara untuk bergerak dengan bola yang dilakukan oleh seorang pemain dan tujuannya untuk membebaskan diri dari lawan atau mencari posisi bagus untuk mengoper atau menembak bola. Dapat disimpulkan dari teori di atas bahwasanya dribble merupakan pengalihan dalam mengecoh lawan sehinga seorang pemain dapat mencari ruang gerak untuk melakukan tembakan dalam mencetak poin.

Berdasarkan pengamatan di lapangan diketahui bahwa kemampuan dirbble dari siswa kelas XI IPS 5 SMA N 3 Mandau Kabupaten Bengkalis masih rendah, banyak di antara mereka yang belum mampu melakukan dribble dengan sempurna. Kesalahan-kesalahan yang dilakukan di antaranya: (1) menundukan kepalanya saat mendribble bola, (2) bola mudah untuk diambil atau direbut, (3) mendribbel bola terlalu tinggi, (4) cara menggiring bola hanya asal-asalan menggiring, (5) terlalu cepat memantulkan bola, (6) sulit mengontrol bola, (7) memukul bola terlalu kuat.

Banyaknya kesalahan yang terjadi mengakibatkan tidak tercapainya KKM bolabasket yang telah ditetapkan yaitu 62, belum adanya pemberian metode audio visual di dalam pembelajaran PJOK. Dengan demikian tampak bahwa tingkat kegagalan dribble dari siswa kelas XI IPS5 SMA N 3 Mandau Kabupaten Bengkalis masih cukup besar. Oleh karena itu, perlu kiranya dipilih pembelajaran yang sesuai dengan krakteristik siswa yang termasuk dalam permainan bolabasket yang masih dalam taraf belajar. Jadi guru harus lebih jeli lagi dalam memilih model pembelajaran yang tepat dan sesuai dengan materi yang disampaikan.

Dalam hal ini, pengunaan media sangat penting bagi peserta didik termotivasi dan mudah untuk mengingat apa yang telah mereka lihat serta mengaplikasikannya dalam kegiatan proses pembelajaran serta bersamangat dalam melakukan materi pembelajaran yang telah disampaikan. Menurut Arsyad (2013); Putra dan Tausikal, (2017) media adalah manusia, materi atau kejadian yang membangun suatu kondisi yang membuat siswa mampu memperoleh pengetahuan, keterampilan, dan sikap. Dalam pengertian ini guru, buku teks, dan lingkungan sekolah merupakan media. Secara khusus, pengertian media dalam grafis, photografis, atau elektronis untuk menangkap, memperoses dan menyusun kembali informasi visual atau verbal. Menurut Rusman dalam Nurwahyuni dan Indahwati (2015) media adalah suatu alat bantu atau perantara yang dapat mewakilkan sesuatu yang akan disampaikan sehingga pesan tersebut akan menjadi lebih mudah diterima, dengan media hal yang akan disampaikan dapat disederhanakan dan diolah secara sederhana. Menurut Sadiman dalam Wahyuningsih \& Susanti (2012) mengatakan media adalah segala sesuatu yang dapat digunakan untuk menyalurkan pesan dari pengirim ke penerima sehinga dapat merangsang siswa sehinga proses belajar terjadi. Sedangkan Hamalik dalam Satin (2014) media adalah sebagai teknik yang digunakan dalam rangka lebih mengefetifkan komunikasi antara guru dan murid dalam proses pendidikan dan pengajaran di sekolah. Dapat disimpulkan menurut kutipan di atas bahwa media merupakan suatu alat yang membantu tugas manusia sebagai pengantar pesan atau informasi kepada banyak orang dan media juga berperan penting dalam perkembanga zaman modren saat ini.

Menurut AECT (Association of Education and Comunication) memberi batasan tentang media sebagai segala bentuk dan saluran yang digunakan untuk menyampaikan pesan 
atau informasi. Disamping sebagai sistem penyampai atau pegantar, media yang sering diganti dengan kata mediator menurut Fleming dalam Arsyad (2013) adalah penyebab atau alat yang turut campur tangan dalam dua pihak dan mendamaikannya dengan istilah mediator media menunjukan fungsi atau perannya, yaitu mengatur hubungan yang efektif antara dua pihak utama, dalam proses belajar siswa dan isi pelajaran. Di samping itu mediator dapat pula mencerminkan pengertian bahwa setiap sistem pembelajaran yang melakukan peran mediasi, mulai dari guru sampai kepada peralatan paling cangih dapat disebut media. Ringkasnya, media adalah alat yang menyampaikan atau mengantarkan pesan-pesan pembelajaran.

Selanjutnya media audio visual adalah media penyampai informasi yang memiliki krakteristik suara dan gambar (Fikriyah, 2015). Adanya unsur audio memungkinkan siswa untuk dapat menerima pesan pembelajaran melalui pendengaran, sedangkan unsur visual memungkinkan penciptan pesan belajar melalui bentuk visualisasi. Mengunakan alat-alat yang ada dengan menunjukan gambar atau vidio yang mempunyai efek suara yang membuat pembelajaran lebih efektif dan efisien. Asmara (2015) mengatakan media audio visual adalah rangkain gambar elektronis yang disertai oleh unsur suara (audio) serta unsur gambar (visual) yang dituangkan dalam pita vidio (vidio tape), rangkain gambar elektronis tersebut kemudian diputar dengan suatu alat yaitu vidio player.

Dalam penelitian Cendra, Gazali, dan Dermawan (2019) menjelaskan bahwa media pembelajaran audio visual memberikan efektivitas yang signifikan terhadap keterampilan teknik dasar bulu tangkis mahasiswa Penjaskesrek Universitas Islam Riau. Begitu juga dalam penelitian Eka \& Sudarso (2015) penggunaan media audio visual dapat diterapkan dalam membantu mengembangkan khayalan mental mengenai suatu gerakan atau keterampilan tertentu, dengan menggunakan media audio visual atau disebut juga dengan media video terdapat dua unsur pesan yang dapat disampaikan sekaligus yaitu audio dan visual. Senada dengan itu Candra dan Henjilito (2018) menyatakan dengan adanya latihan imagery tersebut pemain tim bola voli lebih merasakan ketenangan di dalam melakukan gerakan smash dan lebih berhati-hati dalam smash yang baik serta juga meningkatkan rasa percaya diri mereka.

Tujuan penelitian ini adalah untuk meningkatkan hasil belajar teknik menggiring bolabasket melalui media audio visual pada permainan bolabasket kelas IX IPS 5 SMAN 3 Mandau, sehingga peneliti merasa pentingnya media audio visual ini diberikan dalam pembelajaran olahraga khususnya bola basket. Dengan adanya penerapan media audio visual ini diharapkan bisa membuat semangat siswa dalam belajar menggiring bola basket. Hasil penelitian ini nantinya juga diharapkan dapat dipakai oleh guru penjas ketika mengalami permasalahan yang sama.

\section{METODE PENELITIAN}

Jenis penelitian ini adalah penelitian tindakan kelas, yaitu penelitian yang dilakukan dalam kelas dengan tujuan untuk meningkatkan hasil belajar keterampilan dribble bolabasket melalui media audio visual. Sehingga mencapai nilai KKM 62 yang telah ditetapkan, dengan mengunakan dua siklus dalam penelitian ini. Menurut Arikunto (2011) menyatakan bahwa penelitian tindakan kelas (PTK) adalah penelitian yang dilakukan oleh guru, berkerja sama dengan peneliti (atau dilakukan oleh guru sendiri yang bertindak sebagai peneliti) di kelas atau di sekolah tempat ia mengajar dengan penekanan pada penyempuranaan atau penigkatan proses dan praktis pembelajaran. Dari uraian diatas dapat disimpulkan bahwa penelitian sebagai bentuk infestigasi yang bersifat reflektif, partisipasif, kalaboratif dan spiral. 
Dalam penelitian ini menggunakan beberapa model siklus. Menurut Arikunto (2011) menggemukakan model yang disarankan atau konsep pokok bahwa penelitian ini terdiri dari empat pokok yang menunjukan langkah yaitu: (1) Perencanaan (Plainning), (2) Tindakan (Acting), (3) Pengamatan (Observing), (4) Refleksi. Dalam penelitian tindakan kelas ini yang menjadi subjek penelitian adalah siswa kelas XI IPS5 SMA N 3 Mandau Kabupaten Bengkalis tahun ajaran 2019/2020 yang terdiri dari 35 orang siswa (15 Putera dan 18 Puteri).

Adapun penelitian ini mengunakan teknik model siklus I, siklus II, observasi, dokumentasi, RPP dan rubrik penilian. Analisis data yang dilakukannya itu untuk mengolah, meneliti, melaporkan dan membandingkan hasil penelitian masing masing siklus terhadap hasil belajar sebelum dan sesudah melalui media audio visual dalam dribble permaian bolabasket. Data berupa tes diklarifikasikan sebagai data kuantitatif, data tersebut dianalisis secara deskriptif, yakni dengan membandingkan nilai proses antar siklus, yang dianalisis adalah nilai proses pembelajaran yang telah melalui media audio visual sebanyak dua siklus data yang dibandingkan hasilnya dapat mencapai batas ketercapaian atau indikator keberhasilan yang telah ditetapkan.

Tabel 1: Kisi-Kisi Rubrik Penilaian Teknik Das ar Dribbling Bola Basket

\begin{tabular}{|c|c|c|c|c|}
\hline \multirow{2}{*}{ No } & \multirow{2}{*}{ Tahap } & \multirow{2}{*}{ Aspek Penilaian } & \multicolumn{2}{|c|}{ Skor } \\
\hline & & & 2 & 3 \\
\hline \multirow{3}{*}{1} & \multirow{3}{*}{ Persiapan } & Berdiri dengan sikap melangkah & & \\
\hline & & Badan agak condong ke depan & & \\
\hline & & Berat badan tertumpu pada kaki belakang & & \\
\hline \multirow{3}{*}{2} & \multirow{3}{*}{ Gerakan } & $\begin{array}{l}\text { Doronglah mengunakan telapak tangan ke lantai } \\
\text { dengan sumber gerakan dari sikut dibantu } \\
\text { pergelangantangandiaktifkan. }\end{array}$ & & \\
\hline & & $\begin{array}{l}\text { Ketinggiaan bola memantul adalah sebatas } \\
\text { pinggang atau dibawahpinggang. }\end{array}$ & & \\
\hline & & $\begin{array}{l}\text { Pandangan mata ketika mengiring bola tertuju } \\
\text { bebas ke depan. }\end{array}$ & & \\
\hline 3 & $\begin{array}{c}\text { Akhir } \\
\text { Gerakan }\end{array}$ & Kedua tangan rileks dan badan ditegakan kembali & & \\
\hline Jumlah & & & 21 & \\
\hline
\end{tabular}

Nilai $=\underset{\text { jumlah skor yang diproleh } \times 100}{\text { Jumlah skor maksimal }}$

\section{HASIL PENELITIAN}

Berdasarkan hasil penelitian mengenai upaya meningkat hasil belajar dribble bolabasket melalui media audio visual kelas XI IPS 5 SMAN 3 Mandau sehingga diperoleh hasil pengolahan data yaitu sebagai berikut:

\section{Data Hasil Unjuk Kerja Dribble Bolabasket Pada Siswa Kelas IX IPS 5 SMAN 3 Mandau Pada Siklus I}

Setelah dilakukan pembelajaran dribble bolabasket pada siswa kelas IX IPS 5 SMAN 3 Mandau pada siklus I, diperoleh data yakni: nilai tertinggi pelaksanaan siklus I adalah 90, sedangkan nilai terendah pada siklus I adalah 43. Dimana nilai interval siswa pelaksanaan siklus I di dapat kelas interval antara 43 - 50 dengan 7 siswa atau dengan nilai persentase $25 \%$, nilai interval antara 51 - 58 dengan 12 siswa atau dengan nilai persentase $43 \%$, nilai interval 59 - 66 dengan 4 siswa atau dengan nilai persentase 15\%, nilai interval 67 - 74 dengan 2 siswa atau dengan nilai persentase 7\%, nilai interval 75 - 82 dengan 2 
siswa atau dengan nilai persentase 7\%, nilai interval 83 - 90 dengan 1 siswa atau dengan nilai persentase $3 \%$, Untuk lebih jelas dapat dilihat pada tabel 2 .

Tabel 2. Hasil Penelitian Data Frekuensi Siklus I Dribble Bolabasket Kelas IX IPS 5 SMAN 3 Mandau

\begin{tabular}{cccc}
\hline No & Interval & Frekuensi Absolut & Frekuensi Relatif \\
\hline 1 & $90-83$ & 1 & $3 \%$ \\
\hline 2 & $82-75$ & 2 & $7 \%$ \\
\hline 3 & $74-67$ & 2 & $7 \%$ \\
\hline 4 & $66-59$ & 4 & $14 \%$ \\
\hline 5 & $58-51$ & 12 & $42 \%$ \\
\hline 6 & $50-43$ & 7 & $25 \%$ \\
\hline \multicolumn{7}{r}{} & $\mathbf{2 8}$ & $\mathbf{1 0 0 \%}$ \\
\hline
\end{tabular}

\section{Data Hasil Unjuk Kerja Dribble Bolabasket Pada Siswa Kelas IX IPS 5 SMAN 3 Mandau Pada Siklus II}

Setelah dilakukan pembelajaran dribble bolabasket pada siswa kelas IX IPS 5 SMAN 3 Mandau pada siklus II, diperoleh data yakni: nilai tertinggi pelaksanaan siklus II adalah 86, sedangkan nilai terendah pada siklus I adalah 57. Dimana nilai interval siswa pelaksanaan siklus II di dapat kelas interval antara 57 - 62 dengan 6 siswa atau dengan nilai persentase $31.57 \%$, nilai interval antara 63 - 68 dengan 2 siswa atau dengan nilai persentase 11\%, nilai interval $69-74$ dengan 8 siswa atau dengan nilai persentase $42.10 \%$, nilai interval 75 - 80 dengan 2 siswa atau dengan nilai persentase $11 \%$, nilai interval 81 - 86 dengan 1 siswa atau dengan nilai persentase 5\%, Untuk lebih jelas dapat dilihat pada tabel 3.

Tabel 3. Hasil Penelitian Data Frekuensi Siklus II Dribble Bolabasket Kelas IX IPS 5 SMAN 3 Mandau

\begin{tabular}{|c|c|c|c|}
\hline No & Interval & Frekuensi & Persentase \\
\hline 1 & $86-81$ & 1 & $5 \%$ \\
\hline 2 & $80-75$ & 2 & $11 \%$ \\
\hline 3 & $74-69$ & 8 & $42 \%$ \\
\hline 4 & $68-63$ & 2 & $11 \%$ \\
\hline 5 & $62-57$ & 6 & $31 \%$ \\
\hline & Jumlah & 19 & $100 \%$ \\
\hline
\end{tabular}

\section{Analisis Gerakan Dribble Bolabasket Kelas XI IPS 5 SMAN 3 Mandau Pada Siklus I}

Berdasarkan tes penelitian dribble bolabasket melalui metode media audio visual siswa kelas XI IPS 5 SMAN 3 Mandau pada siklus I dari 28 siswa. Maka nilai siswa yang telah mencapai KKM adalah sebanyak 9 orang dengan persentase 32\%, sedangkan 19 siswa belum mencapai nilai KKM dengan persentase 68\%. Indikator penelitian yaitu; 1 . Tahap Persiapan: a). Berdiri dengan sikap melangkah, dimana skor 3 didapat oleh (2) siswa, skor 2 didapat oleh (15) siswa ,dan skor 1 didapat oleh (11) siswa. b). Badan agak condong ke depan, dimana skor 3 didapat oleh (2) siswa, skor 2 didapat (19) siswa, dan skor 1 didapat oleh (7) siswa. c). Berat badan tertumpu pada kaki belakang, dimana skor 3 didapt oleh (4) siswa, skor 2 didapat (15) siswa, dan skor 1 didapat oleh (9) siswa. 2. Tahap Gerakan: a). Doronglah mengunakan telapak tangan ke lantai dengan sumber gerakan dari sikut atau di bawah pinggang, dimana skor 3 didapat oleh (2) siswa, skor 2 
didapat oleh (15) siswa dan skor 1 didapat oleh (11) siswa. b). Ketinggian bola memantul adalah sebatas pinggang atau di bawah pinggang, dimana skor 3 didapat oleh (2) siswa, skor 2 didapat oleh (18) siswa dan skor 1 didapat oleh (8) siswa. c). Pandangan mata ketika menggiring bola tertuju bebas ke depan, dimana skor 3 didapat oleh (0) siswa, skor 2 didapat oleh (18) siswa dan skor 1 didapat oleh (8) siswa. 3. Tahap Akhir Gerakan: a). Kedua tangan rileks dan badan ditegakkan kembali, dimana skor 3 didapat oleh (1) siswa, skor 2 didapat oleh (18) siswa dan skor 1 didapat oleh (10) siswa. Berdasarkan analisi data pada siklus I, dapat dilihat pada tabel 4 .

Tabel 4. Distribusi Frekuensi Dribble Bolabasket PadaSiswa Kelas XI IPS 5 SMA N 3 Mandau

\begin{tabular}{cccc}
\hline Interval & Jumlah & Persentase & Kategori \\
\hline \multirow{2}{*}{ Siklus I } & 9 & $32 \%$ & Tuntas \\
\cline { 2 - 4 } & 19 & $68 \%$ & Tidak Tuntas \\
\hline
\end{tabular}

\section{Analisis Gerakan Dribble Bolabasket Kelas XI IPS 5 SMA N 3 Mandau Pada Siklus} II

Berdasarkan tes penelitian dribble bolabasket melalui metode media audio visual siswa kelas XI IPS 5 SMAN 3 Mandau pada siklus II dari 19 siswa. Maka nilai siswa yang telah mencapai KKM adalah sebanyak 16 orang dengan persentase 84\%, sedangkan 3 siswa belum mencapai nilai KKM dengan persentase $16 \%$. Indikator penelitian yaitu; 1 . Tahap Persiapan: a). Berdiri dengan sikap melangkah, dimana skor 3 didapat oleh(1) siswa, skor 2 didapat oleh (17) siswa ,dan skor 1 didapat oleh (1) siswa. b). Badan agak condong ke depan, dimana skor 3 didapat oleh (2) siswa, skor 2 didapat (17) siswa dan skor 1 didapat oleh (0) siswa. c). Berat badan tertumpu pada kaki belakang, dimana skor 3 didapat oleh (4) siswa, skor 2 didapat (13) siswa dan skor 1 didapat oleh (2) siswa. 2. Tahap Gerakan: a). Doronglah mengunakan telapak tangan ke lantai dengan sumber gerakan dari sikut atau di bawah pinggang, dimana skor 3 didapat oleh (1) siswa, skor 2 didapat oleh (17) siswa dan skor 1 didapat oleh (1) siswa. b). Ketinggian bola memantul adalah sebatas pinggang atau di bawah pinggang, dimana skor 3 didapat oleh (2) siswa, skor 2 didapat oleh (16) siswa dan skor 1 didapat oleh (1) siswa. c). Pandangan mata ketika menggiring bola tertuju bebas ke depan, dimana skor 3 didapat oleh (3) siswa, skor 2 didapat oleh (14) siswa dan skor 1 didapat oleh (3) siswa. 3. Tahap Akhir Gerakan: a). Kedua tangan rileks dan badan ditegakan kembali, dimana skor 3 didapat oleh (1) siswa, skor 2 didapat oleh (17) siswa dan skor 1 didapat oleh (1) siswa. Berdasarkan analisi data pada siklus II, dapat dilihat pada tabel 5 .

Tabel 5. Dis tribusi Frekuensi Dribble Bolabas ket Pada Sis wa Kelas XI IPS 5 SMA N 3 Mandau

\begin{tabular}{cccc}
\hline Interval & Jumlah & Persentase & Kategori \\
\hline \multirow{2}{*}{ Siklus II } & 16 & $84 \%$ & Tuntas \\
\cline { 2 - 4 } & 3 & $16 \%$ & Tidak Tuntas \\
\hline
\end{tabular}

\section{PEMBAHASAN}

Dari hasil penelitian dari peneliti sendiri, data pada siklus I masih terdapat beberapa siswa yang belum mencapai nilai ketuntasan KKM sebanyak 19 orang siswa, hal tersebut disebabkan oleh adanya beberapa faktor yang menjadi kendala belum tuntasnya (1) sebagian dari anak-anak tersebut masih kaku dalam melakukan dribble hal tersebut disampaikan dari mereka karena telah lama tidak pernah melakukan permainan olahraga basket, (2) penyampaian materi masih tidak mereka pahami dan belum menguasai bagaimana melakukan gerakan dribble yang benar, dengan persentase $68 \%$, 
sedangkan siswa yang mencapai nilai ketuntasan KKM sebanyak 9 orang siswa dengan persentase 32\%, karena sebagian dari mereka ada yang menjadi pemain ekstrakulikuler bolabasket untuk sekolah sehingga membuat jam terbang bermain sudah berpengalaman, ketuntasan klasikal tercapai apabila 80\% dari seluruh siswa dan siswi. Sementara pada penelitian siklus I masih adanya siswa yang belum mampu melakukan teknik dribble bolabasket dengan baik dan benar, dan belum mendapatkan nilai KKM 62 maka kelas tersebut dinyatakan belum tuntas dengan persentase 62\%, selanjutnya dilakukan pada minggu berikutnya masuk ke pada siklus II yang berfokus kepada siswa yang belum mencapai nilai KKM. Dari hasil penelitian pada siklus II terdapat hasil yang sangat signifikan hal tersebut karena guru lebih mefokuskan pada gerakan yang dicontohkan dengan benar serta vidio pembelajaran dribble bolabasket yang lebih menarik membuat mereka menjadi paham gerakan dribble, oleh sebab itu siswa yang mencapai ketuntasan sebanyak 16 orang siswa dari 19 siswa yang awalnya belum tuntas di siklus I, dengan persentase $84 \%$, sementara siswa yang belum mencapai nilai KKM sebanyak 3 orang siswa dengan persentase 16\%. Maka bisa ditarik kesimpulan dari hasil penelitian yang telah dilakukan dengan mengunakan metode audio viusal terdapat hasil yang sangat memuaskan, sehingga mencapai ketuntasan dari siklus I kesiklus II mengalami peningkatan terhadap hasil belajar siswa melakukan teknik dribble bolabasket mengunakan audio visual, maka kelas tersebut dinyatakan tuntas dalam melakukan teknik dribble bola basket.

Menurut Pembayun dan Rachman (2016) untuk meningkatkan kemampuan siswa yang mengikuti ekstakurikuler bolabasket salah satunya adalah mengunakan media audio visual dan didapatkan adanya pengaruh penggunaan media audio visual terhadap hasil belajar dribble bola basket yang signifikan. Penerapan pembelajaran olahraga bolabasket mengunakan metode audio visual dapat memberikan kontribusi yang besar dan signifikan terhadap hasil belajar dribbling bolabasket pada siswa kelas VII 2 SMPN 5 Lima Puluh Kabupaten Batu Bara (Simbolon, 2016). Maka dari itu dengan menerapkan media audio visual pada pembelajaran olahraga bolabasket dapat meningkatkan hasil belajar dribble siswa.

\section{KESIMPULAN}

Beradasarkan hasil analisis data, pertanyaan penelitian dan pembahasan yang telah dikemukakan maka kesimpulan dalam penelitian ini adalah terdapatnya peningkatan keterampilan dribble bolabasket melalui metode media audio visual pada pembelajaran bolabasket Kelas IX IPS 5 SMA N 3 Mandau Kabupaten Bengkalis. Diharapkan kepada peneliti selanjutnya untuk dapat diterapkan pada cabang olahraga lain.

\section{DAFTAR PUSTAKA}

Arikunto. (2011). Penelitian Tindakan Kelas. Jakarta: PT. Bumi Aksara.

Arsyad, A. (2013). Media Pembelajaran.Jakarta: PT. Raja Grafindo Persada.

Asmara, A. P. (2015). Pengembangan Media Pembelajaran Berbasis Audio Visual Tentang Pembuatan Koloid. Jurnal Ilmiah Didaktika, 15(2), 156-178.

Candra, A., \& Henjilito, R. (2018). Pengaruh Latihan Pukulan Menggunakan Imagery Terhadap Hasil Smash Permainan Bolavoli. Journal Sport Area,3(2), 102-110. 
Candra, O., \& Wahyudi. (2020). Motivasi Siswa Mengikuti Kegiatan Ekstrakurikuler Bola Basket di SMP Negeri 9 Pekanbaru. Journal Of Sport Education, 2(2), 70-78.

Cendra, R., Gazali, N., \& Dermawan, M. R. (2019). The effectiveness of audio visual learning media towards badminton basic technical skills. Jurnal SPORTIF: Jurnal Penelitian Pembelajaran, 5(1), 55-69.

Daharis, \& Ramadhani, A. (2018). Peningkatan Hasil Belajar Bermain Bola Basket Melalui Metode Latihan Variasi Pada Pembelajaran Pendidikan Jasmani Siswa SMA Negeri 10 Pekanbaru. Gladi: Jurnal Ilmu Keolahragaan, 9(2), 77-85.

Eka, H., \& Sudarso. (2015). Pengaruh Media Audio Visual Terhadap Penguasaan Teknik Smash Kedeng (Studi Pada Ekstrakurikuler Sepak Takraw SMP Negeri 2 Gedeg Kabupaten Mojokerto). Jurnal Pendidikan Olahraga dan Kesehatan,3(1), 140-146.

Fikriyah. (2015). Media Berbasi Proyek Disertai Media Audio Visual Dalam Pembelajaran Fisika di SMA N 4 Jember. Jurnal Pembelajaran Fisika, 4(2), 181-184.

Foekh, \& Tausikal. (2014). Pendekatan Kontekstual Teaching and Learning Terhadap Hasil Belajar Dribble Bola Baket (Studi Pada SMAK Santo Albertus Malang). Jurnal Pendidikan Olahraga dan Kesehatan, 2(1), 181-184.

Nurwahyuni, \& Indahwati. (2015). Penerapan Media AudioVisual Dalam Gerak Senam Lantai Terhadap Hasil Belajar Siswa. Jurnal Pendidikan Olahraga dan Kesehatan, 3(3), 843-848.

Oliver, J. (2009). Dasar-dasar Bola Basket. Bandung: Pakar Raya.

Pembayun, \& Rachman. (2016). Penerapan Media Audio Visual Terhadap Hasil Dribble Bola Basket (Studi Penelitian Pada Siswa Ekstrakulikuler Bola Basket SMA N 1 Ngunut). Jurnal Pendidikan dan Olahraga Kesehatan, 4(2), 277-282.

Perdima, F. E. (2017). Kontribusi Kelincahan Terhadap Kemampuan Dribbling Bolabasket Atlet SMA Negeri 1 Lebong Utara. Journal Sport Area, 2(1), 1-6. https://doi.org/10.1017/CB09781107415324.004

Putra, \& Tausikal. (2017). Pemanfaatan Media Visual Terhadap Hasil Belajar Bola Basket. Jurnal Pendidikan Olahraga dan Kesehatan, 5(2), 266-271.

Satin, U. (2014). Media Pendidikan, Peran dan Fungsinya Dalam Pembelajaran. Jurnal Tarbawiyah, 1(1), 131-144.

Simbolon, S. N. (2016). Upaya Peningkatan Hasil Belajar Dribbling Bola Basket Melalui Penerapan Media Pembelajaran Audio Visual Pada Siswa Kelas VII-2 SMP Negeri 5 Lima Puluh Kabupaten Batubara Tahun Ajaran 2014/2015. Jurnal Pendidikan dan Olahraga, 1(3), 277-318. 
Edu Sportivo: Indonesian Journal of Physical Education

Faizan Ramadhan et al., 1(1), 50-59 [2020]

Wahyuningsih, \& Susanti. (2012). Pengembangan Media Pembelajaran Vidio Sebagai Bahan Penagamatan Berbasi Animasi Pada Jurnal Penyusuaian. Jurnal Pendidikan Akuntasi, 1(1), 1-6.

Wissel, H. (2000). Bola Basket. Jakarta: PT. Raja Grafindo Persada. 